\title{
Recommending Oral Probiotics to Reduce Winter Antibiotic Prescriptions in People With Asthma: A Pragmatic Randomized Controlled Trial
}

\author{
Timotby D. H. Smith, MBBCh, \\ MRCGP, MSc ${ }^{1}$ \\ Hilary Watt, CStat, MSc, MA ${ }^{2}$ \\ Laura Gunn, PbD, MS, BA ${ }^{3}$ \\ Josip Car, MD, $\mathrm{PbD}, \mathrm{DIC}, \mathrm{MSc} \mathrm{c}^{2}$ \\ Robert J. Boyle, MBCbB, MRCPCH, \\ $\mathrm{PbD}{ }^{4}$
}

'Harambee Surgery, NHS East Lancashire CCG, Lancashire, United Kingdom

${ }^{2}$ Department of Primary Care and Public Health, Imperial College London, London, United Kingdom

${ }^{3}$ Integrative Health Science, Stetson University, DeLand, Florida

${ }^{4}$ Department of Paediatrics, Imperial College London, London, United Kingdom

Conflicts of interest: authors report none.

\section{CORRESPONDING AUTHOR}

Robert J. Boyle, MBChB Wright Fleming Building Imperial College London Norfolk Place

London W2 1PG

r.boyle@nhs.net

\begin{abstract}
PURPOSE Evidence from studies mainly in children has shown that orally administered probiotics may prevent respiratory tract infections and associated antibiotic use. We evaluated whether advice to take daily probiotics can reduce antibiotic prescribing for winter respiratory tract infections in people with asthma.
\end{abstract}

METHODS We conducted a randomized controlled, parallel-group pragmatic study for participants aged 5 years and older with asthma in a UK primary care setting. The intervention was a postal leaflet with advice to take daily probiotics from October 2013 to March 2014, compared with a standard winter advice leaflet. Primary outcome was the proportion of participants prescribed antibiotics for respiratory tract infections.

RESULTS There were 1,302 participants randomly assigned to a control group $(n=650)$ or intervention group $(n=652)$. There was no significant difference in the primary outcome measure, with $27.7 \%$ receiving antibiotics in the intervention group and $26.9 \%$ receiving antibiotics in the control group (odds ratio $=1.04 ; 95 \% \mathrm{Cl}, 0.82-1.34)$. Uptake of probiotics was low, but outcomes were similar in those who accessed probiotics (adjusted odds ratio $=1.08 ; 95 \%$ $\mathrm{Cl}, 0.69-1.69$, compared with controls). We also found no evidence of an effect on respiratory tract infections or asthma exacerbations.

CONCLUSIONS In this pragmatic community-based trial in people with asthma, we found no evidence that advising use of winter probiotics reduces antibiotic prescribing.

Ann Fam Med 2016;14:422-430. doi: 10.1370/afm.1970.

\section{INTRODUCTION}

A cute respiratory tract infection is the most common reason for attending primary care appointments and accounts for $80 \%$ of antibiotic prescriptions. ${ }^{1}$ A Cochrane review in 2011 found that, in randomized controlled trials (RCTs) of specific patient populations, probiotic prophylaxis significantly reduces both upper respiratory tract infections (URTIs) and antibiotic prescribing rates for these infections. ${ }^{2}$ We wanted to determine whether giving advice to take regular probiotics is an effective strategy for reducing antibiotic prescribing rates for respiratory tract infections in people with asthma, most of whom are older than the predominantly young child populations analyzed in the Cochrane review. People with asthma are especially vulnerable to viral URTIs, which are the most common trigger of acute asthma exacerbations ${ }^{3}$ and contribute substantially to the burden of unnecessary antibiotic prescriptions. Only 1 previous pilot study assessed effects of probiotics (combined with acupuncture) on respiratory tract infection rates in people with asthma. In this trial, reduced infection rates were found with the intervention, but the study was underpowered $(\mathrm{n}=17)$, and the findings were not statistically significant $(P=.18)^{4}$ Probiotics alone for preventing antibiotic use in asthmatics have not, to our knowledge, been evaluated in a prospective controlled trial. ${ }^{4.7}$ 
We undertook a pragmatic trial to assess whether advice to take probiotic treatment, implemented as part of routine winter infection advice, could reduce antibiotic prescription rates and respiratory tract infections in older children and adults with asthma in a primary care setting.

\section{METHODS}

\section{Study Design}

This study was a parallel-group prospective RCT of a pragmatic community-based intervention-advice leaflets including recommendations to take a probiotic supplement daily through the winter months-for reducing antibiotic prescription in participants with asthma.

\section{PARTICIPANTS}

All participants were registered patients at Ashfields Primary Care Centre, a semiurban practice in the United Kingdom caring for 23,000 patients with a nationally representative socioeconomic and racial mix. Inclusion criteria were age 5 years or older (because a diagnosis of asthma in preschool children is unreliable), a current diagnosis of asthma, ${ }^{8}$ and a random selection of 1 person per household only. All patients in the practice population registered with a current diagnosis of asthma and fulfilling the inclusion criteria were enrolled in the study.

\section{Ethics and Consent}

The study was approved by London-Bloomsbury Research Ethics Committee (reference 13/LO/0783). Informed consent was not obtained from study participants, although they were given the option to request that their data were not included in study analyses.

\section{Randomization, Treatment Allocation, and Blinding}

Where there was more than 1 eligible participant per household, the participant was selected randomly. For included participants, the randomization sequence was computer generated with a 1-to-1 intervention-tocontrol ratio in random block sizes of 4,6 , and 8 , stratified by age (ages 5 to 18,19 to 34,35 to 59 , and $\geq 60$ years). Clinical staff and the outcome assessor were blinded to treatment allocation until all study data had been entered, cleaned, and locked in the study database to be sent to the study statistician.

\section{Study Intervention}

In the United Kingdom, all patients with asthma are invited to receive annual influenza vaccination. In this study, participants were sent information leaflets (Supplemental Appendix 1, http://www.annfammed.org/
content/14/5/422/suppl/DC1) during a 2-week period in late September 2013, together with their routine invitation for annual influenza vaccination. Participants randomized to the control group received a leaflet with standard advice about measures that have been reported to help reduce infections or asthma exacerbations. ${ }^{9-15}$ Participants randomized to the intervention group received an information leaflet with an additional section recommending taking $1 \mathrm{Lab} 4$ (Cultech Ltd) probiotic capsule daily from October to the end of March. In addition, the intervention group received 3 tokens with which they could request 2 months of supplies at a time from the manufacturer via telephone or Internet, which are the methods by which Lab4 is currently sold. Lab4 is a patented blend of 4 probiotic bacteria comprising 2 strains of Lactobacillus acidopbilus CUL60 (NCIMB 30157) and CUL21 (NCIMB 30156), Bifidobacterium bifidum CUL20 (NCIMB 30153) and B animalis (var lactis) CUL34 (NCIMB 30172) at a total $2.5 \times$ $10^{10}$ colony-forming units per capsule.

\section{Outcome Measures}

All outcome measures were prespecified in the statistical analysis plan, which was finalized before database lock. The primary outcome measure was the proportion of participants who, within the 6-month period for which probiotics were recommended, were prescribed at least 1 new course of 1 of the following antibiotics locally used for respiratory tract infections: amoxicillin, azithromycin, cefaclor, cephalexin, ciprofloxacin, clarithromycin, co-amoxiclav, doxycycline, erythromycin, or phenoxymethylpenicillin. Secondary outcomes were based on consultations for URTIs, lower respiratory tract infections (LRTIs), asthma exacerbation or any respiratory tract infection, and the number and cost of antibiotic courses prescribed during the 6-month intervention period. Full outcome measures, along with methods used to define different forms of respiratory tract infection, asthma exacerbations, and new episodes of illness, are described in Supplemental Appendix 2, http://www. annfammed.org/content/14/5/422/suppl/DC1.

Outcome data were extracted from participants' medical records for the 6 -month period when probiotic consumption was recommended, October 1, 2013, to March 31, 2014, by a single investigator blinded to treatment allocation.

\section{Statistical Analysis}

In the study primary care practice, $28.4 \%$ of all patients with a current asthma diagnosis had received 1 or more of the specified antibiotics during the winter before this study (October 2012 to March 2013). The Cochrane systematic review found probiotics are associated with reduced antibiotic prescribing for acute 
URTI compared with placebo (relative risk $[R R]=0.67$; 95\% CI, 0.45-0.98). ${ }^{2}$ For an $80 \%$ power to detect a smaller effect size $(R R=0.77)$ in this pragmatic study, with anticipated $20 \%$ loss of outcome data and a $5 \%$ contamination rate in the control group, we planned to randomize 1,258 participants.

Intention-to-treat analysis included all participants with data available for the relevant outcome in the groups to which they were originally assigned, regardless of whether they took the intervention. Per protocol analyses were used to compare 2 subgroupsparticipants who ordered probiotics 1 or more or 2 or more times-with the control group. Adjusted analyses used logistic regression for binary outcomes, linear regression for continuous outcome variables, and $t$ tests for cost data with boot-strapping to provide robust confidence intervals on these estimates. Variables

\section{Figure 1. CONSORT flow diagram showing participant recruitment and flow through the study.}

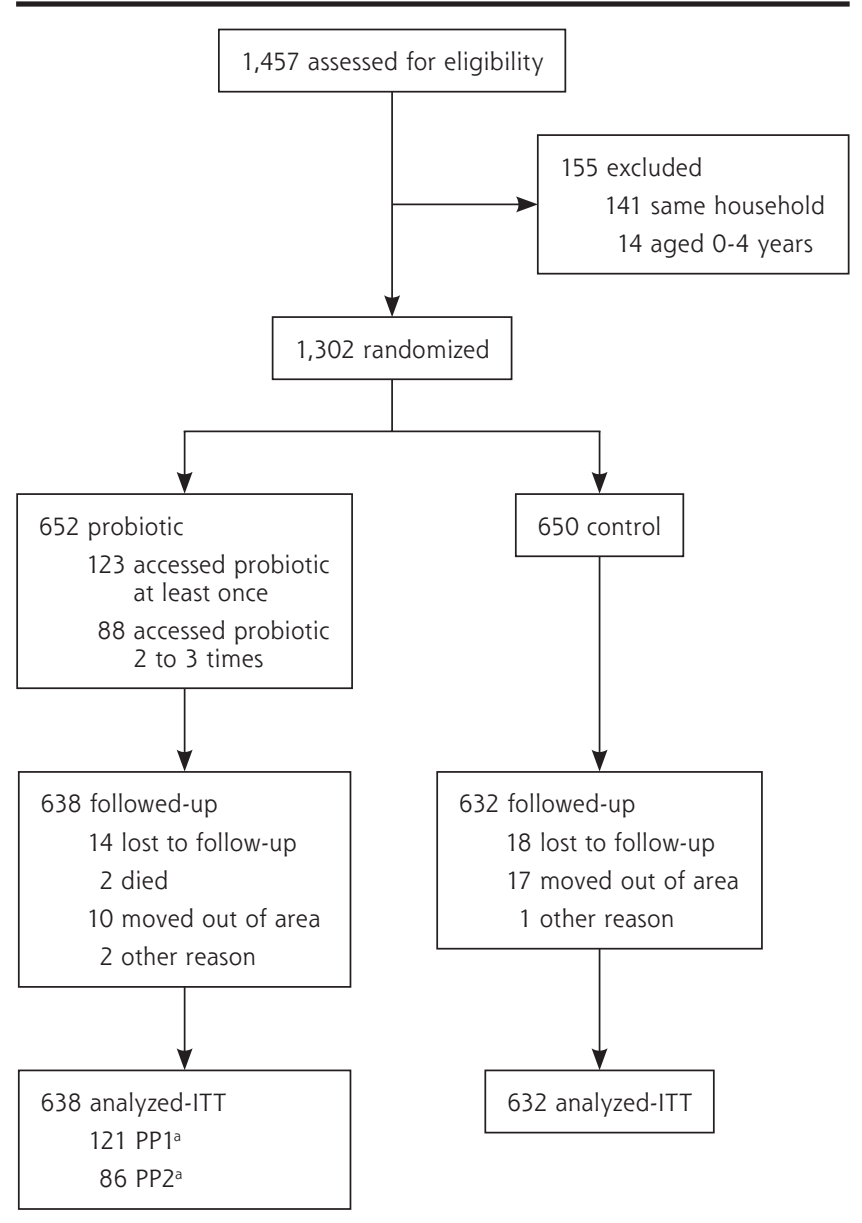

CONSORT $=$ Consolidated Standards of Reporting Trials; PP = per protocol; ITT = intention to treat.

a PP1 is 1 or more sets of probiotics ordered; PP2 is 2 or more sets of probiotics ordered. Each set included sufficient probiotics for 2 months. adjusted for were age-group, sex, asthma severity (see Supplemental Appendix 3, http://www.annfammed. org/content/14/5/422/suppl/DC1), and numbers of courses of any antibiotics prescribed in the 12 months before entry into the trial. Sensitivity analyses further adjusted for receiving influenza vaccine during the trial. Multiple comparisons were assessed using the Hochberg procedure to control for false discovery. ${ }^{16}$

\section{RESULTS}

Recruitment and flow of participants are displayed in Figure 1. Losses to follow-up were low-14 (2.1\%) participants in the intervention group 18 (2.8\%) in the control group. Primary analyses included the remaining 1,270 participants (638 intervention; 632 control), with the 2 fatalities also included in adverse events analysis. The recommended probiotic was accessed by $121(19.0 \%)$ participants in the intervention group at least once (2 or more months' supply), and $86(13.5 \%)$ at least twice (4 or more months' supply). Blinding and contamination are discussed in Supplemental Appendix 4, http://www. annfammed.org/content/14/5/422/suppl/DC1.

\section{Outcome of Randomization}

Table 1 shows the baseline characteristics of both randomization groups with few significant differences between randomized groups. The participants who accessed probiotics in the intervention group-used for per protocol analyses-show some differences from the control group. They were generally older and had asthma diagnosed later in life, and they were more likely to have had an asthma review and influenza vaccine in the last 12 months. There was no significant difference between groups in the proportion of prescribed antibiotics in the last 12 months or in other chronic disease rates, when adjusted for age and sex.

\section{Effect of the Study Intervention on Antibiotic Use}

Table 2 shows the study outcomes relating to antibiotic use for the intention-to-treat and per protocol analyses. We found no difference between treatment groups in our primary outcome measure-prescription of a specified antibiotic during the study period-in intention-totreat (odds ratio $[\mathrm{OR}]=1.04 ; 95 \% \mathrm{CI}, 0.82-1.34$ ) or per protocol analyses for 1 or more probiotic token used (adjusted odds ratio [AOR] 1.08; 95\% $\mathrm{CI}, 0.69-1.69)$ or 2 or more probiotic tokens used (AOR 1.04; 95\% CI, 0.62-1.75; Figure 2). We also 
found no difference in secondary outcomes-use of any antibiotic, any antibiotic given for URTI or any respiratory tract illness, number of antibiotic courses, or total cost of antibiotics - in unadjusted or adjusted analyses. We found weak evidence for a higher mean number of respiratory tract episodes for which antibiotics were given in the intervention (intention-to-treat) group compared with the control group (ie, a detrimental effect), but when adjusted for multiple testing this was not found to be significant. ${ }^{16}$ For the 10 separate antibiotic outcomes evaluated, the threshold is $P=.005$, using the false discovery method of Hochberg.

\section{Table 1. Baseline Characteristics of Study Participants}

\begin{tabular}{|c|c|c|c|c|}
\hline Characteristic & $\begin{array}{l}\text { Randomized } \\
\text { Control Group } \\
(n=650)\end{array}$ & $\begin{array}{c}\text { Randomized } \\
\text { Intervention Group } \\
(n=652)\end{array}$ & $\begin{array}{l}\text { Obtaining any } \\
\text { Probiotic Package } \\
\qquad(n=123)\end{array}$ & $\begin{array}{l}\text { Obtaining } 2-3 \\
\text { Probiotic Packages } \\
(n=88)\end{array}$ \\
\hline \multicolumn{5}{|l|}{ Age-group, y } \\
\hline 5-18, No. (\%) & $80(12)$ & $80(12)$ & $10(8)$ & $7(8)$ \\
\hline 19-34, No. (\%) & $95(15)$ & $101(15)$ & $7(6)$ & $2(2)$ \\
\hline 35-59, No. (\%) & 254 (39) & $251(38)$ & $34(28)$ & $21(24)$ \\
\hline$\geq 60$, No. (\%) & $221(34)$ & $220(34)$ & $72(59)$ & $58(66)$ \\
\hline Age, median (range), ${ }^{a} y$ & $48(32-66)$ & $49(32-65)$ & $64(46-70)^{b}$ & $65(54-74)^{\mathrm{b}}$ \\
\hline Male, No, (\%) & $277(43)$ & $316(49)^{c}$ & $52(42)$ & $42(48)$ \\
\hline Body mass index, median (range) & $\begin{array}{l}26.8 \\
(23.5-30.7)\end{array}$ & $\begin{array}{l}27.2 \\
(24.2-30.7)\end{array}$ & $\begin{array}{l}28.2 \\
(25.0-31.2)\end{array}$ & $\begin{array}{l}27.4 \\
(24.9-30.9)\end{array}$ \\
\hline $\begin{array}{l}\text { Age when asthma diagnosed, } \\
\text { median (range), }{ }^{a} y\end{array}$ & $31(11-52)$ & $33(11-50)$ & $46(30-59)^{b}$ & $47(31-61)^{b}$ \\
\hline \multicolumn{5}{|l|}{ Ethnic group } \\
\hline White, No. (\%) & 577 (89) & $595(91)$ & 109 (89) & $82(93)$ \\
\hline Black, No. (\%) & $2(0.3)$ & $1(0.2)$ & $0(0)$ & $0(0)$ \\
\hline Asian, No. (\%) & $4(0.6)$ & $1(0.2)$ & $0(0)$ & $0(0)$ \\
\hline Mixed, No. (\%) & $45(7)$ & $39(6)$ & $12(10)$ & $6(7)$ \\
\hline Not specified, No. (\%) & $22(3)$ & $16(3)$ & $2(2)$ & $0(0)$ \\
\hline \multicolumn{5}{|l|}{ Smoking status } \\
\hline Never smoked, No. (\%) & $385(60)$ & $368(57)$ & $76(62)$ & $54(61)$ \\
\hline Ex-smoker, No. (\%) & $188(29)$ & $200(31)$ & $37(30)$ & $29(33)$ \\
\hline Current smoker, No. (\%) & $66(10)$ & $67(10)$ & $7(6)$ & $3(3)$ \\
\hline Not specified, No. (\%) & $11(2)$ & $17(3)$ & $3(2)$ & $2(2)$ \\
\hline \multicolumn{5}{|l|}{ Asthma severity } \\
\hline Step 1, No. (\%) & $103(16)$ & $116(18)$ & $15(12)$ & $7(8)$ \\
\hline Step 2 or 3, No. (\%) & $283(44)$ & $272(42)$ & $51(42)$ & $41(47)$ \\
\hline Step 3 or 4, No. (\%) & $202(31)$ & $207(32)$ & $40(33)$ & $27(31)$ \\
\hline Step 5, No. (\%) & $62(9)$ & $57(9)$ & $16(13)$ & $13(15)$ \\
\hline \multicolumn{5}{|l|}{ Other disease registers } \\
\hline Diabetes mellitus, No. (\%) & $56(9)$ & $37(6)^{c}$ & $5(4)$ & $4(5)$ \\
\hline Coronary heart disease, No. (\%) & $36(6)$ & $32(5)$ & $10(8)$ & $9(10)$ \\
\hline Stroke or TIA, No. (\%) & $11(2)$ & $17(3)$ & $2(2)$ & $1(1)$ \\
\hline COPD, No. (\%) & $43(7)$ & $46(7)$ & $9(7)$ & $8(9)$ \\
\hline Cancer, No. (\%) & $31(5)$ & $37(6)$ & $13(11)^{c}$ & $9(10)^{c}$ \\
\hline Rheumatoid arthritis, No. (\%) & $5(0.8)$ & $4(0.6)$ & $1(0.8)$ & $1(1)$ \\
\hline \multicolumn{5}{|l|}{ In last 12 mo } \\
\hline Any antibiotics, No. (\%) & $330(51)$ & $327(50)$ & $71(58)$ & $55(63)^{c}$ \\
\hline Oral corticosteroids, No. (\%) & $132(20)$ & $123(19)$ & $26(21)$ & $21(24)$ \\
\hline Asthma review, No. (\%) & $377(58)$ & $373(57)$ & $86(70)^{c}$ & $64(73)^{d}$ \\
\hline Influenza vaccine, No. (\%) & $416(64)$ & $409(63)$ & $98(80)^{b}$ & $72(82)^{b}$ \\
\hline \multicolumn{5}{|c|}{ COPD = chronic obstructive pulmonary disease; $\mathrm{TIA}=$ transient ischemic attack. } \\
\hline \multicolumn{5}{|c|}{ Note: Comparisons are made between randomized groups and for those within the intervention group who obtained probiotic packages at least once, and 2 to 3 times. } \\
\hline $\begin{array}{l}\text { a Range of } 25 \text { th to } 75 \text { th percentile. } \\
\text { b } P<.001 . \\
\text { c } P<.05 \\
\text { d } P<.01 \text { comparing intervention group } \\
\text { significant. }\end{array}$ & protocol groups obt & probiotics with the control & (unadjusted analysis). No & such comparisons were \\
\hline
\end{tabular}


Table 2. Effects of Advice to Take Probiotics on Antibiotic Prescribing Outcomes

\begin{tabular}{|c|c|c|c|c|}
\hline Outcome & $\begin{array}{l}\text { Randomized } \\
\text { Control Group } \\
\text { (n=632) } \\
\text { No. }(\%)\end{array}$ & $\begin{array}{c}\text { Randomized } \\
\text { Intervention Group } \\
(n=638) \\
\text { No. }(\%)\end{array}$ & $\begin{array}{c}\text { Obtaining Any } \\
\text { Probiotic Package } \\
\text { (n }=121) \\
\text { No. }(\%)\end{array}$ & $\begin{array}{c}\text { Obtaining } 2-3 \\
\text { Probiotic Packages } \\
(n=86) \\
\text { No. }(\%)\end{array}$ \\
\hline Taken any selected antibiotic & $170(26.9)$ & $177(27.7)$ & $38(31.4)$ & $28(32.6)$ \\
\hline Taken any antibiotic & $212(33.5)$ & $216(33.9)$ & $46(38)$ & $32(37.2)$ \\
\hline $\begin{array}{l}\text { Had URTI without wheeze, } \\
\text { treated by antibiotics }\end{array}$ & $27(4.3)$ & $30(4.7)$ & $5(4.1)$ & $4(4.7)$ \\
\hline \multirow{2}{*}{$\begin{array}{l}\text { Had respiratory episode, } \\
\text { treated by antibiotics }\end{array}$} & $129(20.4)$ & $143(22.4)$ & $31(25.6)$ & $24(27.9)$ \\
\hline & Mean No. $(\%)^{d}$ & Mean No. $(\%)^{d}$ & Mean No. $(\%)^{d}$ & Mean No. $(\%)^{d}$ \\
\hline Selected antibiotic course & $0.42(17.4,9.5)$ & $0.47(16.3,11.4)$ & $0.50(9.8,11.6)$ & $0.51(19.8,12.8)$ \\
\hline Any antibiotic course & $0.59(19.6,13.9)$ & $0.61(19.0,14.9)$ & $0.64(24.0,14.0)$ & $0.63(20.9,16.3)$ \\
\hline $\begin{array}{l}\text { URTI without wheeze given } \\
\text { antibiotic course }\end{array}$ & $0.04(4.1,0.2)$ & $0.05(4.1,0.6)$ & $0.04(4.1,0.0)$ & $0.05(4.7,0.0)$ \\
\hline \multirow{2}{*}{$\begin{array}{l}\text { Combined all respiratory } \\
\text { episodes given antibiotic } \\
\text { course }\end{array}$} & $0.23(18.2,2.2)$ & $0.30(16.1,6.3)^{e}$ & $0.32(19.0,6.6)$ & $0.35(20.9,7.0)$ \\
\hline & Mean $\mathrm{E}(\mathrm{SD})$ & Mean $€(S D)$ & Mean $€$ (SD) & Mean $\mathrm{E}(\mathrm{SD})$ \\
\hline $\begin{array}{l}\text { Total cost per person of } \\
\text { selected antibiotic }\end{array}$ & $1.49(10.9)$ & $1.75(16.58)$ & $4.41(37.18)$ & $5.74(44.08)$ \\
\hline $\begin{array}{l}\text { Total cost per person of all } \\
\text { antibiotics }\end{array}$ & $2.41(11.68)$ & 2.38 (16.96) & $4.74(37.18)$ & $5.98(44.07)$ \\
\hline
\end{tabular}

$\mathrm{AOR}=$ adjusted odds ratio; Diff = difference; $I R R=$ incidence rate ratio; URTI = upper respiratory tract infection.

Note: Comparison is made between randomized groups comparing the intervention group with the control group, and the randomized control group with the per protocol groups after additional advice and obtaining probiotic.

a From unadjusted analyses.

b From analyses adjusted for age-group, sex, asthma severity and use of any antibiotics in 12 months before study.

\section{Figure 2. Summarized effect size for the study primary outcome.}

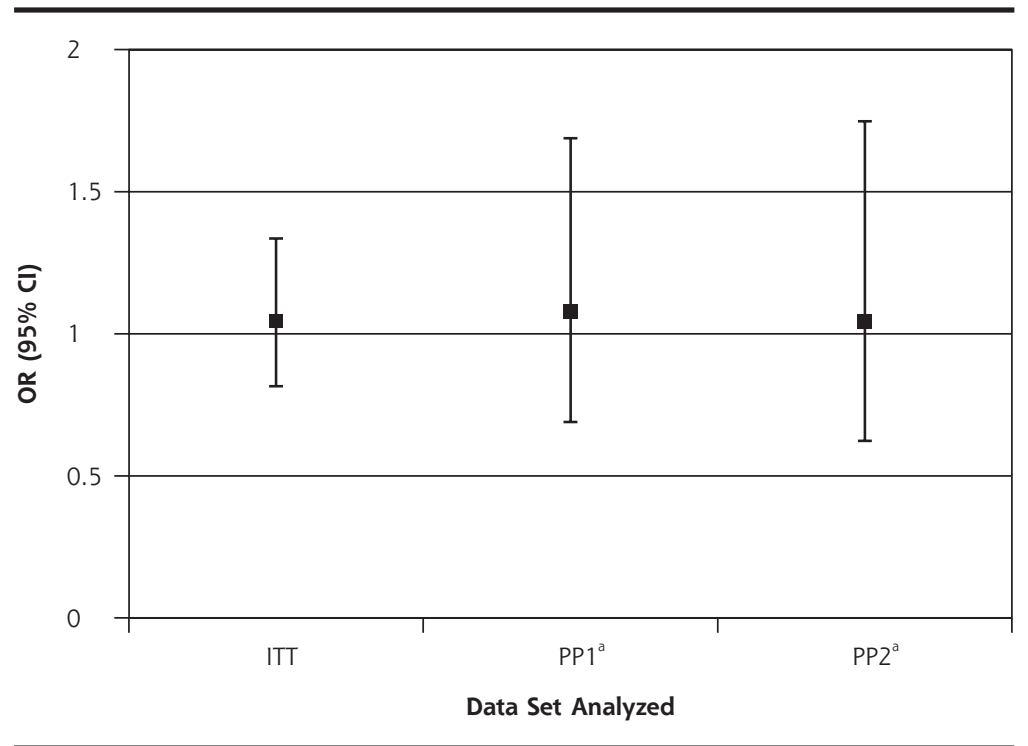

$\mathrm{ITT}=$ intention to treat; $\mathrm{OR}=$ odds ratio; $\mathrm{PP}=$ per protocol

Note: Data represent the OR $(95 \% \mathrm{Cl})$ for 1 or more antibiotic prescriptions during the 6 -month intervention period compared with control group. OR is unadjusted for the ITT analysis, and adjusted for agegroup, sex, asthma severity, and use of any antibiotics in the 12 months before the study for per protocol analyses.

a PP1 is 1 or more sets of probiotics ordered; PP2 is 2 or more sets of probiotics ordered. Each set included sufficient probiotics for 2 months.
Effect of the Study Intervention on Respiratory Tract Health

Table 3 shows outcomes related to respiratory tract health for the intention-to-treat and per protocol analyses. We found no difference between treatment groups in respiratory tract outcomes: any URTI, any asthma exacerbation, any respiratory tract infection, or total episodes of each of these categories in intentionto-treat or per protocol analyses, using unadjusted or adjusted analyses. We found weak evidence for detrimental effects in the intervention group in the number of people with an LRTI and mean number of LRTIs per person, but these were not significant when adjusted for multiple testing (threshold for respiratory tract outcomes $P=.0125){ }^{16}$

\section{Adverse Effects of the Intervention}

There was no significant difference in serious adverse events between 


\begin{tabular}{|c|c|c|}
\hline $\begin{array}{l}\text { Randomized } \\
\text { Intervention Group } \\
\text { OR }(95 \% \mathrm{Cl})^{c}\end{array}$ & $\begin{array}{l}\text { Obtaining Any } \\
\text { Probiotic Package } \\
\text { AOR }(95 \% \mathrm{Cl})^{c}\end{array}$ & $\begin{array}{l}\text { Obtaining } 2-3 \\
\text { Probiotic Packages } \\
\text { AOR }(95 \% \mathrm{Cl})^{\mathrm{c}}\end{array}$ \\
\hline $1.04(0.82$ to 1.34$)$ & 1.08 (0.69 to 1.69$)$ & 1.04 (0.62 to 1.75$)$ \\
\hline $1.01(0.80$ to 1.28$)$ & 1.09 (0.71 to 1.68$)$ & $0.97(0.58$ to 1.6$)$ \\
\hline 1.11 (0.65 to 1.88$)$ & $1.15(0.42$ to 3.12$)$ & 1.54 (0.5 to 4.72 ) \\
\hline 1.13 (0.86 to 1.47$)$ & $1.16(0.72$ to 1.87$)$ & 1.20 .7 to 2.06 ) \\
\hline IRR $(95 \% \mathrm{Cl})^{\mathrm{c}}$ & IRR $(95 \% \mathrm{Cl})^{\mathrm{c}}$ & IRR $(95 \% \mathrm{CI})^{\mathrm{c}}$ \\
\hline 1.11 (0.88 to 1.38$)$ & $1.02(0.71$ to 1.46$)$ & 0.97 (0.64 to 0.46$)$ \\
\hline $1.03(0.84$ to 1.26$)$ & 0.95 (0.69 to 1.32$)$ & 0.88 (0.6 to 1.29$)$ \\
\hline 1.24 (0.72 to 2.12$)$ & 1.08 (0.41 to 2.83$)$ & 1.36 (0.47 to 3.99$)$ \\
\hline 1.31 (1.03 to 1.66$)$ & $1.24(0.87$ to 1.78$)$ & 1.26 (0.84 to 1.88$)$ \\
\hline Diff, $€(95 \% \mathrm{Cl})^{f}$ & Diff, $\mathrm{f}(95 \% \mathrm{Cl})^{\mathrm{f}}$ & Diff, $\in(95 \% \mathrm{Cl})^{\mathrm{f}}$ \\
\hline $0.25(-1.29$ to 1.79$)$ & $2.33(-3.80$ to 8.46$)$ & $3.50(-5.26$ to 12.27$)$ \\
\hline$-0.04(-1.62$ to 1.54$)$ & $1.74(-3.84$ to 8.51$)$ & $2.81(-5.14$ to 12.15$)$ \\
\hline
\end{tabular}

' Compared with the randomized control group.

d Percentages with 1 , with 2 or more.

e $P<.05$ compared with the control group.

'Compared with the randomized control group with boot-strapped confidence interval.

younger children that probiotics reduce respiratory tract infections and resulting antibiotic prescription rates, and they cast doubt on the reproducibility of those findings in older children and adults with asthma using information leaflets. Our data suggest that real-world use of probiotics to prevent winter infections and reduce antibiotic use cannot yet be recommended despite positive findings in a Cochrane review-at least not in older children and adults with asthma. Winter infections are not necessarily all captured, as we only analyze those reported to the physician. There is little reason to believe, however, that there would be differential reporting of infections between treatment arms. Antibiotic prescriptions are generally captured data, because they would appear in general practice records, so this more important outcome is collected robustly.

The 2011 Cochrane systematic review found participants treated with probiotics had a reduced risk of antibiotic use for acute URTIs ( $R R=0.67$; $95 \% \mathrm{CI}, 0.45-0.98)$ and for 1 or more URTIs (OR $=0.55 ; 95 \% \mathrm{CI}, 0.35-0.86){ }^{1}$

treatment groups (Table 4) when corrected for multiple testing. ${ }^{16}$ This finding is further discussed in Supplemental Appendix 5, http://www.annfammed.org/ content/14/5/422/suppl/DC1.

\section{DISCUSSION}

In this pragmatic RCT of a recommendation for adults and older children with asthma to take daily probiotics during a single winter, we found no evidence that the intervention of advice leaflets recommending probiotic supplementation, with free access to such supplements, can reduce antibiotic prescriptions or promote improved respiratory tract health. Although only approximately $20 \%$ of these participants followed the intervention leaflet advice and took probiotics (per protocol groups), we found no evidence that probiotics influenced study outcomes in the per protocol groups. It is possible that those who accessed the probiotic would have had more respiratory tract infections and resulting antibiotics without the probiotic, but adjustment for likely confounding factors failed to show any evidence to support this likelihood (see also Supplemental Appendix 6, http://www.annfammed.org/ content/14/5/422/suppl/DC1). These results differ from previous findings in controlled trials mainly involving
Our data challenge this finding-our 95\% confidence intervals do not overlap with the point estimate of the odds ratios or relative risks of the Cochrane review. Differences between our study and those in the Cochrane review include the age-group studied, our focus on people with asthma, the probiotic strain(s) used, and our pragmatic trial design - the use of information leaflets and the offer of free probiotics.

The developing immune system at younger ages may be more sensitive to immunological changes in the gastrointestinal tract triggered by taking probiotics, ${ }_{1}^{17}$ and $95 \%$ of subjects included in the Cochrane review were aged under 8 years compared with only $3 \%$ in our study. Three recent RCTs published subsequent to the Cochrane review found positive effects of probiotics in pediatric populations when used to prevent respiratory tract infections. ${ }^{18-20}$ The studies in the Cochrane review $^{1}$ also included very few people with asthma, and it is possible that the immunopathology of asthma leads to a differential response to probiotics. ${ }^{21,22}$ One small pilot study suggested probiotics may have positive effects in asthma, although the inconclusive findings were due to low statistical power. ${ }^{4}$

All 3 studies included in the meta-analysis on antibiotic prescribing in the Cochrane review, and all 4 studies in another meta-analysis showing similar 
Table 3. Effects of Advice to Take Probiotics on Respiratory Outcomes Not Related to Antibiotic Prescriptions

\begin{tabular}{|c|c|c|c|c|}
\hline Outcome & $\begin{array}{c}\text { Randomized } \\
\text { Control Group } \\
(n=632) \\
\text { No. }(\%)\end{array}$ & $\begin{array}{c}\text { Randomized } \\
\text { Intervention Group } \\
(n=638) \\
\text { No. }(\%)\end{array}$ & $\begin{array}{c}\text { Obtaining Any } \\
\text { Probiotic Package } \\
(\mathrm{n}=121) \\
\text { No. }(\%)\end{array}$ & $\begin{array}{c}\text { Obtaining } 2-3 \\
\text { Probiotic Packages } \\
(n=86) \\
\text { No. }(\%)\end{array}$ \\
\hline Had any URTI without wheeze & $43(6.8)$ & $48(7.5)$ & $11(9.1)$ & $7(8.1)$ \\
\hline Had any LRTI without wheeze & $63(10.0)$ & $87^{d}(13.6)$ & $17(14.0)$ & $11(12.8)$ \\
\hline Had any asthma exacerbations, wheeze & $85(13.4)$ & $84(13.2)$ & $19(15.7)$ & $15(17.4)$ \\
\hline Had any respiratory infection & $177(28.0)$ & $188(29.5)$ & $40(33.1)$ & $29(33.7)$ \\
\hline Received influenza vaccine during trial & $430(68.0)$ & $454(71.2)$ & $111(91.7)^{\mathrm{e}}$ & $78(90.7)^{f}$ \\
\hline \multirow[t]{2}{*}{ Received asthma review during trial } & $221(35.0)$ & $207(32.4)$ & $47(38.8)$ & $36(41.9)$ \\
\hline & Mean No. $(\%)^{g}$ & Mean No. $(\%)^{g}$ & Mean No. (\%) ${ }^{g}$ & Mean No. $(\%)^{g}$ \\
\hline URTIs without wheeze & $0.08(5.4,1.4)$ & $0.09(6.6,0.9)$ & $0.09(9.1,0.0)$ & $0.08(8.1,0.0)$ \\
\hline LRTIs without wheeze & $0.12(8.5,1.4)$ & $0.1(10.8,2.8)^{d}$ & $0.17(10.7,3.3)$ & $0.15(10.5,2.3)$ \\
\hline Asthma exacerbations or wheeze & $0.17(11.1,2.4)$ & $0.16(10.5,2.7)$ & $0.18(13.2,2.5)$ & $0.21(14.0,3.5)$ \\
\hline Total respiratory episodes & $0.37(21.4,6.6)$ & $0.42(20.5,8.9)$ & $0.45(24.0,9.1)$ & $0.44(24.4,9.3)$ \\
\hline
\end{tabular}

$\mathrm{AOR}=$ adjusted odds ratio; IRR = incidence rate ratio; $\mathrm{LRTI}=$ lower respiratory tract infection; URTI = upper respiratory tract infection.

Note: Comparison is made between randomized groups comparing the intervention group with the control group and between the per protocol groups of participants after additionaladvice and obtaining probiotics during the study, to the randomized control group.

From unadjusted analyses.

From analyses adjusted for age-group, sex, asthma, severity, any use of any antibiotics in 12 months before the study.

evidence for a benefit, evaluated L rhamnosus GG, in some instances in conjunction with a second probiotic, $B$ lactis Bb-12. ${ }^{23}$ Immune effects of probiotics may be species- or strain- rather than genus-specific. ${ }^{24,25}$ It is also possible that publication bias, which is difficult to assess in meta-analyses of small numbers of studies, or time-lag bias may have contributed to the Cochrane review's findings. ${ }^{26}$ We identified a data-entry error in the 2011 Cochrane review and an issue of differential loss to follow-up-an assumption that the $18.3 \%$ in the probiotic group and $4.6 \%$ in the control group who were lost to follow-up would all have had no URTIsboth relating to the included studies of Hao et $\mathrm{al}^{2}$ and Cobo Sanz et al ${ }^{27}$ (Supplemental Appendix 7, http:// www.annfammed.org/content/14/5/422/suppl/DC1).
Together with our negative trial findings, these issues support a need to update the Cochrane systematic review of probiotics for URTI.

One final explanation for the difference between our findings and those of previous studies may be the use of intact probiotic capsules or tablets rather than a liquid formulation. Only 1 of 2 RCTs in the Cochrane review using a nonliquid probiotic formulation for prevention of respiratory tract infections showed a benefit in reducing URTIs. ${ }^{28,29}$ Since then, 1 other RCT showed reduced symptoms of URTIs using probiotic capsules ${ }^{20}$ although it is unclear whether the young participants dissolved the capsules' powder contents in liquid, as other pediatric studies have done. ${ }^{30}$ If probiotics prevent URTI through local effects on the upper

Table 4. Serious Adverse Events

\begin{tabular}{|c|c|c|c|c|c|c|c|c|}
\hline \multirow[b]{2}{*}{ Event Category } & \multicolumn{2}{|c|}{$\begin{array}{c}\text { Randomized Control } \\
\text { Group } \\
(n=632)\end{array}$} & \multicolumn{2}{|c|}{$\begin{array}{c}\text { Randomized } \\
\text { Intervention Group } \\
(n=640)\end{array}$} & \multicolumn{2}{|c|}{$\begin{array}{c}\text { Obtaining Any Probiotic } \\
\text { Package } \\
(n=122)\end{array}$} & \multicolumn{2}{|c|}{$\begin{array}{c}\text { Obtaining } 2-3 \\
\text { Probiotic Packages } \\
(n=87)\end{array}$} \\
\hline & No. & $\%(95 \% \mathrm{Cl})$ & No. & $\%(95 \% \mathrm{Cl})$ & No. & $\%(95 \% \mathrm{Cl})$ & No. & $\%(95 \% \mathrm{Cl})$ \\
\hline Respiratory & 10 & $1.6(0.8-2.9)$ & 6 & $0.9(0.3-2.0)$ & 1 & $0.8(0.02-4.5)$ & 1 & $1.1(0.03-6.2)$ \\
\hline Gastrointestinal & 6 & $0.9(0.3-2.1)$ & 10 & $1.6(0.8-2.9)$ & 0 & $0.0(0.0-3.0)$ & 0 & $0(0-4.2)$ \\
\hline $\begin{array}{l}\text { Infection (excluding } \\
\text { above) }\end{array}$ & 2 & $0.3(0.04-1.1)$ & 4 & $0.6(0.2-1.6)$ & 2 & $1.6(0.2-5.8)$ & 1 & $1.1(0.03-6.2)$ \\
\hline Other & 20 & $3.2(1.9-4.8)$ & 31 & $4.8(3.3-6.8)$ & $10^{a}$ & $8.2(4.0-14.6)$ & 6 & $6.9(2.6-14.4)$ \\
\hline
\end{tabular}


Acknowledgments: We are grateful to Jean Pointon from Ashfields Primary Care Centre, NHS South Cheshire CCG, United Kingdom, for administrative support especially with treatment allocation. We are grateful to Susan Plummer from Cultech Ltd, Swansea, UK, for agreeing to supply Lab4 probiotics) for this study without charge. Robert J. Boyle is supported by the National Institute for Health Research Biomedical Research Centre, and the MRC-Asthma UK Centre for Allergic Mechanisms in Asthma.

Supplemental materials: Available at http://www. annfammed.org/content/14/5/422/suppl/DC1/.

\section{References}

1. Cosby JL, Francis N, Butler CC. The role of evidence in the decline of antibiotic use for common respiratory infections in primary care. Lancet Infect Dis. 2007;7(11):749-756.

2. Hao Q, Lu Z, Dong BR, Huang CQ, Wu T. Probiotics for preventing acute upper respiratory tract infections. Cochrane Database Syst Rev. 2011;(9):006895. http://dx.doi. org/10.1002/14651858.CD006895.pub2. Published Sep 7، 2011. Accessed Sep 8, 2011.

3. Busse WW, Lemanske RF Jr, Gern JE. Role of viral respiratory infections in asthma and asthma exacerbations. Lancet. http://www.sciencedirect.com/science/article/pii/S01406 73610613803. Published Sep 2010. Accessed Nov 5, 2014.

respiratory tract mucosa, then direct contact between probiotic and mucosa may be important for efficacy.

There is a need for new ways to prevent URTI and reduce antibiotic prescribing in asthmatic and nonasthmatic patients that are cost-effective, safe, and acceptable to patients. In a population of people with asthma, we found that probiotics were not effective in preventing antibiotic prescription, in contrast to the findings of the Cochrane review. We also found no effect on URTI, LRTI, or asthma exacerbation rates. Our data suggest that probiotics may not be effective for prophylaxis against URTIs and cast doubt on the reproducibility of earlier positive trials. There is, therefore, currently not enough evidence to recommend their use for preventing infections and antibiotic use in such at-risk populations as asthmatics. Further work is needed to evaluate whether specific probiotic formulations modulate systemic immune responses or mucosal defenses before developing new interventions to reduce the burden of respiratory tract infection.

To read or post commentaries in response to this article, see it online at http://www.annfammed.org/content/14/5/422.

Key words: infectious disease; respiratory tract infections; respiratory system: asthma; health promotion; preventive health services; probiotics; antibiotic prescribing

Submitted September 29, 2015; submitted, revised, February 21, 2016; accepted April 1, 2016.

Funding support: Lab4 (now rebranded as Proven Probiotics) probiotics were provided for free by Cultech Ltd for those who requested them as part of this study rather than the normal charge.
4. Stockert K, Schneider B, Porenta G, Rath R, Nissel H, Eichler I. Laser acupuncture and probiotics in school age children with asthma: a randomized, placebo-controlled pilot study of therapy guided by principles of Traditional Chinese Medicine. Pediatr Allergy Immunol. 2007;18(2):160-166.

5. Chen YS, Jan RL, Lin YL, Chen HH, Wang JY. Randomized placebocontrolled trial of lactobacillus on asthmatic children with allergic rhinitis. Pediatr Pulmonol 2010;45:(11) 1111-1120. http://dx.doi.org/10.1002/ ppul.21296. Published Oct 26, 2010. Accessed Oct 27, 2010.

6. Giovannini M, Agostoni C, Riva E, et al.; Felicita Study Group. A randomized prospective double blind controlled trial on effects of long-term consumption of fermented milk containing Lactobacillus casei in pre-school children with allergic asthma and/or rhinitis. Pediatr Res. 2007;62(2):215-220.

7. Wheeler JG, Shema SJ, Bogle ML, et al. Immune and clinical impact of Lactobacillus acidophilus on asthma. Ann Allergy Asthma Immunol. 1997;79(3):229-233.

8. NHS Commissioning Board, BMA, NHS Employers. Asthma (AST). In: Quality and Outcomes Framework Guidance for GMS Contract 2013/14. London, England: NHS Employers; 2013:88-94.

9. Clark NM, Lynch JP, 3rd. Influenza: epidemiology, clinical features, therapy, and prevention. Semin Respir Crit Care Med. 2011;32:(4) 373-392. http://dx.doi.org/10.1055/s-0031-1283278. Published Aug 19, 2011. Accessed Aug 22, 2011.

10. Bueving HJ, Thomas S, Wouden JC. Is influenza vaccination in asthma helpful? Curr Opin Allergy Clin Immunol. 2005;5(1):65-70.

11. Cook GW. This winter make the common cold less common: Advice to help you stay healthy. Asthma Mag. 2004;9(6):9-11.

12. Health Protection Agency. Infection control precautions to minimise transmission of Respiratory Tract Infections (RTIs) in the healthcare setting. http://www.hpa.org.uk/webc/hpawebfile/ hpaweb_c/1317131892566. Published Jan 12, 2012. Accessed Jan 25, 2013.

13. Jefferson T, Del Mar CB, Dooley L, Ferroni E, Al-Ansary LA, Bawazeer GA, et al. Physical interventions to interrupt or reduce the spread of respiratory viruses. Cochrane Database of Syst Rev. 2011;(7):006207. http://dx.doi.org/10.1002/14651858.CD006207. pub4. Published Jul 6, 2011. Accessed Jul 7, 2011. 
14. Yardley L, Miller S, Schlotz W, Little P. Evaluation of a Web-based intervention to promote hand hygiene: exploratory randomized controlled trial. J Med Internet Res. 2011;13(4):e107.

15. Melani AS, Bonavia M, Cilenti V, et al; Gruppo Educazionale Associazione Italiana Pneumologi Ospedalieri. Inhaler mishandling remains common in real life and is associated with reduced disease control [published correction appears in Respir Med. 2012;106(5):757]. Respir Med. 2011;105(6):930-938.

16. Benjamini Y, Drai D, Elmer G, Kafkafi N, Golani I. Controlling the false discovery rate in behavior genetics research. Behav Brain Res. 2001;125(1-2):279-284.

17. Singh M, Ranjan Das R. Probiotics for allergic respiratory diseasesputting it into perspective, Pediatr Allergy Immunol. 2010;21(2 Pt 2):e368-e376.

18. Kumpu $M$, Kekkonen RA, Kautiainen $H$, Järvenpää S, Kristo $A$, Huovinen $\mathrm{P}$, et al. Milk containing probiotic Lactobacillus rhamnosus GG and respiratory illness in children: a randomized, doubleblind, placebo-controlled trial. European Journal of Clinical Nutrition. 2012;66:(9) 1020-1023. http://dx.doi.org/10.1038/ejcn.2012.62. Published Sep 2012. Accessed Sep 7, 2012.

19. Maldonado J, Cañabate $F$, Sempere L, Vela F, Sánchez AR, Narbona E, et al. Human milk probiotic Lactobacillus fermentum CECT5716 reduces the incidence of gastrointestinal and upper respiratory tract infections in infants. [published correction appears in J Ped Gastr Nit. 2012;54(4):571(5):757]. JPed Gastr Nit. 2012;54:(1) 55-61. http:// dx.doi.org/10.1097/MPG.0b013e3182333f18. Published Jan 2012. Accessed Dec 28, 2011.

20. Rerksuppaphol S, Rerksuppaphol L. Randomized controlled trial of probiotics to reduce common cold in schoolchildren. Pediatrics International [Online] 2012;54:(5) 682-687. http://onlinelibrary.wiley. com/doi/10.1111/j.1442-200X.2012.03647.x/abstract Published Jul 10, 2012. Accessed Sep 25, 2012.

21. Das RR, Naik SS, Singh M. Probiotics as additives on therapy in allergic airway diseases: a systematic review of benefits and risks. BioMed Research International. 2013;2013:231979. http://www. hindawi.com/journals/bmri/2013/231979/. Published Jul 15, 2013. Accessed Aug 19, 2013.
22. Jacquet A. Probiotic-derived factors: efficient treatment for allergic asthma? Clinical \& Experimental Allergy. 2013;43:(3) 268-270. http:// dx.doi.org/10.1111/cea.12078. Published Feb 17, 2013. Accessed Feb 18, 2013.

23. Liu S, Hu P, Du X, Zhou T, Pei X. Lactobacillus rhamnosus GG supplementation for preventing respiratory infections in children: a meta-analysis of randomized, placebo-controlled trials. Indian Pediatr. 2013;50(4):377-381.

24. Popova M, Molimard P, Courau S, Crociani J, Dufour C, Le Vacon F, et al. Beneficial effects of probiotics in upper respiratory tract infections and their mechanical actions to antagonize pathogens. Journal of Applied Microbiology. 2012;113(6):1305-1318. http://dx.doi. org/10.1111/j.1365-2672.2012.05394.x Published Aug 3, 2012. Accessed Nov 19, 2012.

25. Villena J, Oliveira ML, Ferreira PC, Salva S, Alvarez S. Lactic acid bacteria in the prevention of pneumococcal respiratory infection: future opportunities and challenges. Int Immunopharmacol. 2011;11(11):1633-1645. http://dx.doi.org/10.1016/j. intimp.2011.06.004. Published Jun 25, 2011. Accessed Oct 28, 2011.

26. Dwan K, Gamble C, Williamson PR, Kirkham JJ, Reporting Bias G. Systematic review of the empirical evidence of study publication bias and outcome reporting bias - an updated review. PLOS ONE. 2013;8:(7) e66844. http://dx.doi.org/10.1371/journal. pone.0066844. Published Jul 5, 2013. Accessed Jul 17, 2013.

27. Cobo Sanz JM, Mateos JA, Muñoz Conejo A. [Effect of Lactobacillus casei on the incidence of infectious conditions in children]. Nutr Hosp. 2006;21(4):547-551.

28. de Vrese $M$, Winkler $P$, Rautenberg $P$, et al. Effect of Lactobacillus gasseri PA 16/8, Bifidobacterium longum SP 07/3, B. bifidum MF 20/5 on common cold episodes: a double blind, randomized, controlled trial. Clin Nutr. 2005;24(4):481-491.

29. West NP, Pyne DB, Cripps AW, et al. Lactobacillus fermentum (PCC) supplementation and gastrointestinal and respiratory-tract illness symptoms: a randomised control trial in athletes. Nutr J. 2011;10(1):30.

30. Hatakka K, Blomgren K, Pohjavuori S, et al. Treatment of acute otitis media with probiotics in otitis-prone children-a double-blind, placebo-controlled randomised study. Clin Nutr. 2007;26(3):314-321. 